\title{
UNIDADE DE AR CONDICIONADO PROJETADA PARA VEÍCULOS AUTOMOTORES EQUIPADOS COM SOLUÇÃO START-STOP: MANUTENÇÃO DA PERCEPÇÃO DE CONFORTO DO USUÁRIO ALIADO À RACIONALIZAÇÃO DO CONSUMO DE COMBUSTÍVEL
}

\author{
Luis Fernando Baumgartner ${ }^{1}$, Edison Tsutomu Miyauchi ${ }^{1}$ e Paulo André Simões Aguiar ${ }^{1}$ \\ ${ }^{1}$ Behr Brasil Ltda. \\ E-mails: luis.baumgartner@behrgroup.com, Edison.miyauchi@behrgroup.com, \\ Paulo.aguiar@behrgroup.com
}

\section{RESUMO}

Com o objetivo de reduzir o consumo de combustível e consequentemente os níveis de emissões de $\mathrm{CO}_{2}$, um número crescente de veículos passou a ser equipado com a função StartStop, que desliga o motor quando o veículo está parado (e entra em regime de marcha lenta). Em tais veículos, a manutenção do conforto no habitáculo fica comprometida uma vez que o compressor do sistema de ar condicionado desliga-se juntamente com o motor. Adicionalmente, a estratégia de controle usualmente aplicada nos sistemas Start-Stop prioriza o conforto do usuário, partindo o motor quando a temperatura do habitáculo se eleva, reduzindo assim o benefício para o consumo de combustível. Este artigo apresenta um sistema de ar condicionado que se utiliza de um evaporador com um acumulador integrado e preenchido por um material cujas características físicas permitem que este mude de fase quando a temperatura na região do evaporador começa a subir. Desta forma proporciona um prolongamento no tempo de fornecimento de ar frio para o habitáculo. Mantendo-se a sensação de conforto, a fase de motor desligado (função "Stop") pode ser prolongada e assim reduzir efetivamente do consumo de combustível. Resultados de testes serão apresentados de forma a ilustrar a manutenção do conforto no habitáculo.

\section{INTRODUÇÃO}

O consumo de combustível torna-se, a cada dia, um atributo mais relevante no quadro geral de desempenho de um veículo automotor. Regulamentações governamentais mais severas pressionam a redução do volume de emissões de $\mathrm{CO}_{2}$ da mesma forma que a escalada dos preços dos combustíveis nos direciona a buscar alternativas tecnológicas que priorizem a utilização de combustíveis renováveis, mas possíveis de serem implantadas em larga escala, quer seja quanto à infraestrutura necessária e disponível, quer seja quanto ao montante de investimento demandado do consumidor final. Adicionalmente, demandas governamentais no sentido de mensurar o volume de emissões bem como estabelecer padrões de elegibilidade à redução da carga tributária (na forma dos programas de etiquetagem veicular e do Inovar Auto) renovam a necessidade pela busca de alternativas técnicas viáveis que proporcionem a manutenção da competitividade do portfólio ofertado pelas montadoras de veículos. 
Diante desses fatos a indústria automotiva tem alocado grandes orçamentos na pesquisa e desenvolvimento de novas tecnologias de propulsão para seus veículos que vão desde a melhoria dos motores a combustão interna (ICE), passando por sistemas híbridos de propulsão, células de combustível até o veículo completamente elétrico. Vale ressaltar que a discussão sobre o melhor caminho a seguir permanece viva como esclarece um levantamento publicado pela Boston Consulting Group [1] que apontava perspectivas contraditórias que ora afirmavam que as justificativas para a adoção dos sistemas de propulsão híbridos "violavam as leis da física", ora afirmavam que, por volta do ano de 2020, somente veículos híbridos seriam comercializados.

A figura 1 mostra as alternativas tecnológicas na direção da completa eletrificação do veículo ao mesmo tempo em que ilustra as classificações dos chamados veículos híbridos (ou dotados de um sistema híbrido de propulsão). Vale ressaltar que as tecnologias não são excludentes: embora adjacentes, elas podem sobrepor-se ao longo to caminho. Ainda nessa figura podemos ver que o primeiro passo rumo a eletrificação do veículo é o "Mild-Hybrid" dotado de um pequeno motor elétrico para o sistema Start-Stop e que recupera a energia da frenagem, armazenando-a na bateria, seguido pelo "Full-Hybrid", "Plug-in-Hybrid", "Range Extender" e finalmente o veículo completamente elétrico (EV). Adicionalmente a essa classificação, temos o "Micro-Hybrid", termo que foi cunhado para caracterizar um veículo normalmente dotado de um motor avançado de combustão interna e de um sistema Start-Stop (muito embora, em essência não pudesse ser caracterizado como híbrido [2], passou a ser incluído nessa categoria).

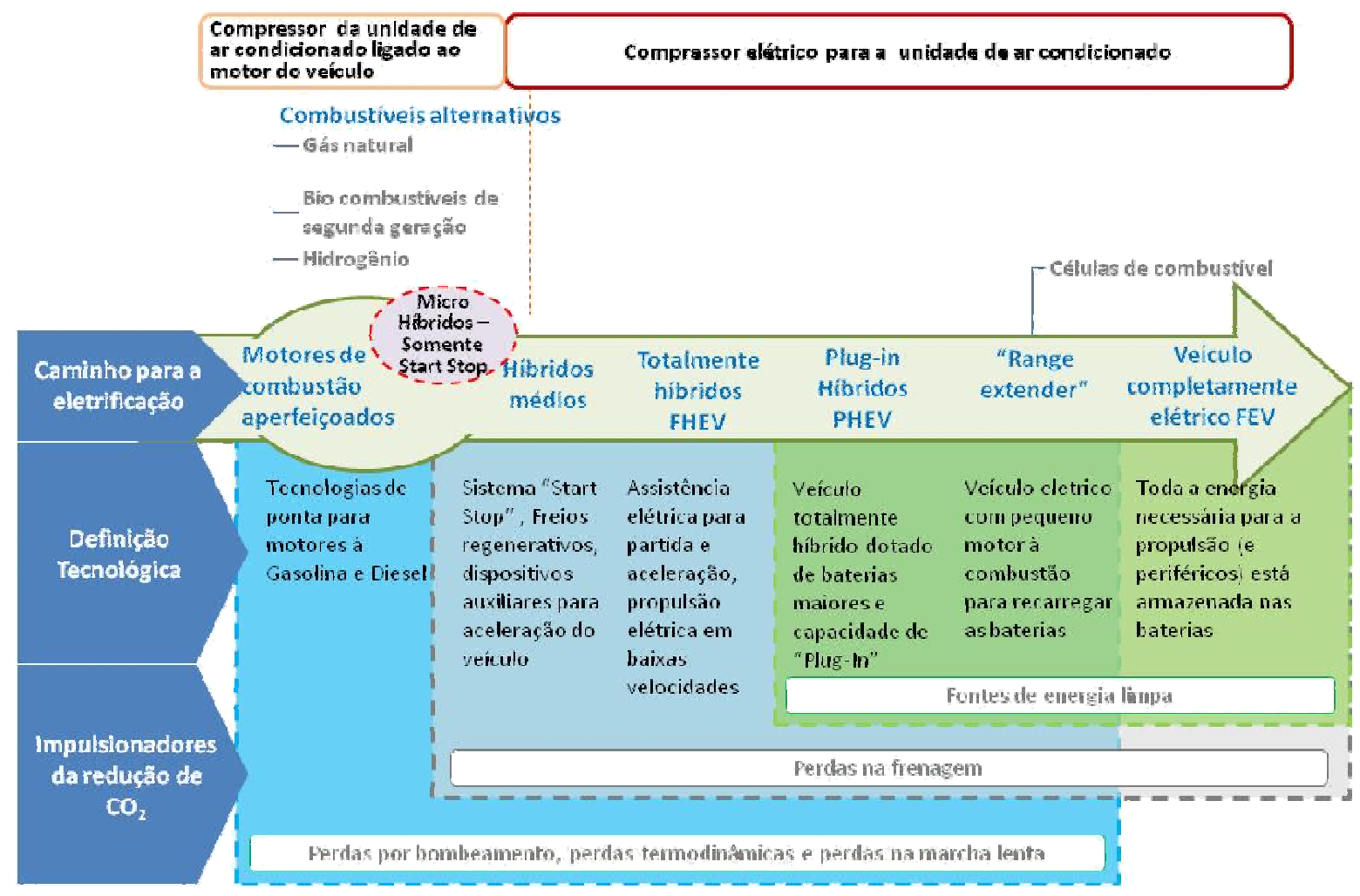

Figura 1:As alternativas tecnológicas no sentido da eletrificação. Adaptado pelos autores de "The comeback of the electric car?: How real, how soon and what must happen next , January 2009 - 
O sistema Start-Stop tem como principal característica o desligamento do motor de combustão interna quando o veículo está estacionado e em marcha lenta, condições comumente encontradas nos congestionamentos (além dos semáforos). Como vimos na figura 1, o sistema Start-Stop está presente em todas as configurações de veículos híbridos e completamente elétricos, incluindo o micro-híbrido (vale ressaltar que, para veículos classificados a partir do "Mild-Hybrid" podemos ter compressores elétricos para o circuito de ar-condicionado). Quando olhamos para as definições tecnológicas que caracterizam os veículos chamados micro-híbridos notamos que ele não dispõe de dispositivos acessórios que habilitam e/ou potencializam a geração ou recuperação de energia (tais como baterias e sistemas regenerativos), portanto todos os periféricos que necessitam de energia para seu acionamento e que estão sob o capô continuam dependentes do motor de combustão interna.

Avaliações de mercado mais recentes confirmam a concentração e preferência por tecnologias voltadas ao aperfeiçoamento dos motores de combustão interna uma vez que estes apresentam melhores compromissos de custo aliados ao benefício da redução de consumo de combustível [1]. Dentro desse cenário, os veículos dotados de motor à combustão interna e dispositivo Start-Stop (também chamados de "Micro-Hybrids" ou micro-híbridos) possuem um papel importante no curto e no médio prazo. Assim, pesquisa conduzida pela IMS Research [3] confirma a relevância dos veículos micro-híbridos (dotados de motor à combustão interna e dispositivo Start-Stop) no portfólio de produção de veículos elétricos (incluindo todas as classes), como mostra a figura 2 , chegando a responder, em 2020, por até $89 \%$ da produção mundial de veículos híbridos e elétricos.

\section{Produção mundial: Veículos dotados de motores avançados à combustão + Start-Stop VERSUS Veículos elétricos}

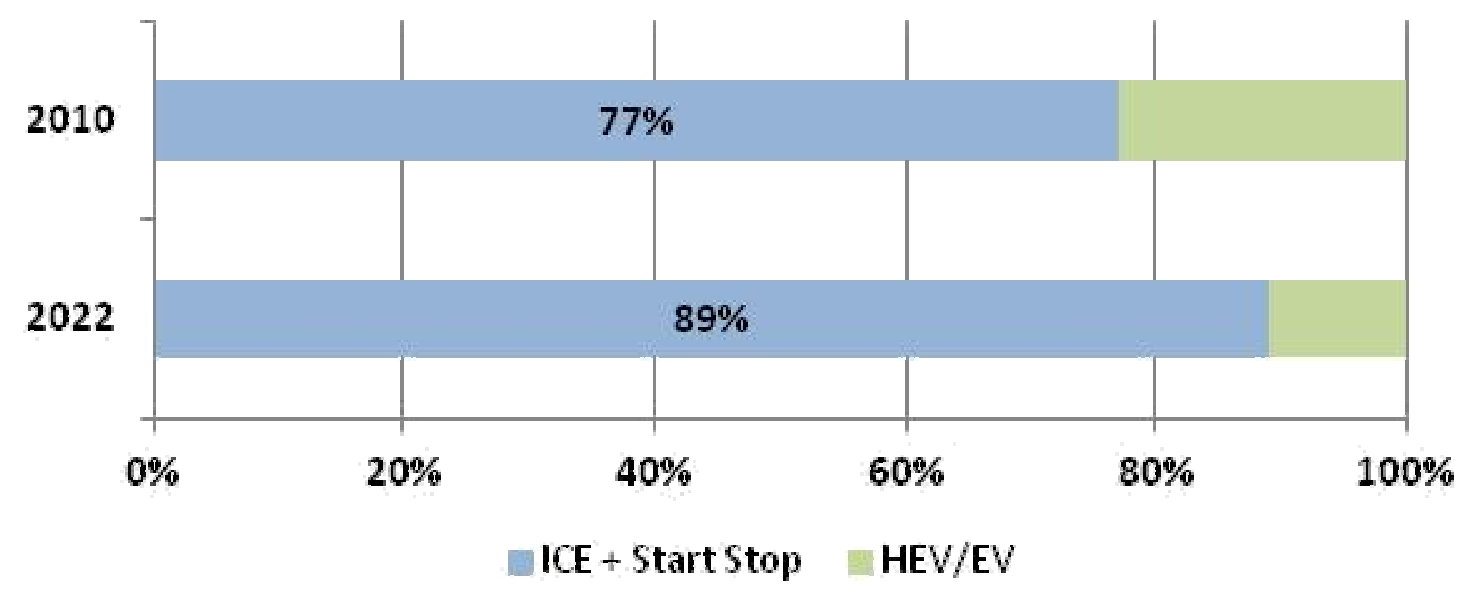

Figura 2: Projeção da participação dos "Micro-Hybrids" (ICE+Start Stop) na produção mundial total de veículos híbridos e completamente elétricos. Fonte: Relatório "Press release" IMS "Micro-hybrids to be dominant hybrid vehicle type for next 10 years" datado de 04.12.2012 (acesso em 04.04.2013)

Nos veículos dotados de Start-Stop, o motor desligado é o principal direcionador da redução no consumo de combustível, porém, com o desligamento do motor, os periféricos a ele acoplados e dependentes da energia por ele gerada também são desligados. Este é o caso do compressor do circuito de ar-condicionado que uma vez desligado permite que a temperatura da cabine se eleve muitas vezes a patamares desconfortáveis para os usuários. Como fator 
complicador, temos que a maioria das lógicas de controle dos veículos privilegia o conforto do usuário em detrimento do consumo de combustível, ou seja, a temperatura da cabine tem precedência, portanto tão logo esta atinja níveis de desconforto, o sistema de controle anulará a função "Stop" e acionará o motor de combustão, anulando quaisquer potenciais de redução no consumo de combustível.

A utilização do ar condicionado aumenta o consumo de combustível em um veículo convencional em torno de $35 \%$ e pode ser caracterizado como uma das mais significantes cargas auxiliares (superando até mesmo a resistência à rolagem e cargas relacionadas ao coeficiente de arraste aerodinâmico do veículo) imputadas ao propulsor do veículo [4]. Estudo realizado nos Estados Unidos estima o uso anual de 7 bilhões de galões de gasolina (27 bilhões de litros) para o acionamento do ar condicionado [5], dessa forma, um bom projeto do sistema de ar condicionado passa a ser altamente relevante e de extrema importância para a efetiva redução consumo de combustível percebida pelo usuário final.

Na sequencia mostraremos potenciais melhorias em elementos de projeto de um circuito de ar condicionado do veículo que proporcionam o prolongamento do fornecimento do ar frio do sistema de ar condicionado para veículos dotados de motor a combustão + sistema Start-Stop, detalhando particularmente um elemento central, o evaporador com acumulador integrado. Concluiremos apresentando resultados de avaliação em veículo efetuadas na Europa bem como discutiremos a necessidade do aprofundamento e da particularização voltada para as condições predominantes no Brasil.

\section{INFORMAÇÕES GERAIS}

Como alternativa viável para a obtenção dos incentivos tributários relacionados com a redução do consumo de combustível, veículos com motores aperfeiçoados de combustão interna e dotados de sistema Start-Stop (micro-híbridos) mostram-se como as melhores opções, balanceando investimentos e tempo de lançamento no mercado para o médio prazo (2022) e proporcionando a manutenção da percepção de segurança: os micro-híbridos não dependem de uma infraestrutura de redes de abastecimento (que ainda não está posta), tampouco de dispendiosas soluções de baterias. Eles estão prontos agora e têm plenas condições de atingir os objetivos demandados, no médio prazo, pelas legislações [3].

Como mencionamos na seção anterior, com o desligamento do motor também temos periféricos a ele acoplados sendo desligados, como por exemplo, o compressor da linha de ar condicionado. O desligamento traz como efeito a elevação da temperatura da cabine, que após sucessivas seções de Start-Stop pode estabilizar-se em patamares característicos que definem a percepção de desconforto pelo usuário final. Para resolver essa situação, as lógicas de controle podem determinar a supressão do desligamento do motor (anulando a função "Stop") e assim privilegiar a manutenção da percepção de conforto pelo usuário. Dessa forma os intervalos de desligamento são espaçados para que haja tempo de ação suficiente para a unidade de ar condicionado manter refrigerado o habitáculo. Claramente, quando há um maior espaçamento (e por vezes, anulação) do desligamento do motor, os benefícios alardeados de redução no consumo de combustível são drasticamente reduzidos. Vale ressaltar que esse efeito é muito mais sensível em condições de trânsito pesado, típicas das grandes regiões metropolitanas (ciclos urbanos). Portanto, a correta caracterização do ciclo de avaliação é fundamental para a efetiva mensuração dos resultados a serem obtidos. 
Há inúmeras medidas que podemos adotar no sentido de aperfeiçoar o projeto e desenvolvimento de uma unidade de ar condicionado que responda mais satisfatoriamente às condições impostas pelos veículos dotados de solução Start-Stop e que ainda mantém como única fonte de geração de energia, o motor de combustão interna (veículos micro-híbridos), dentre elas destacaremos a seguir o evaporador dotado de acumulador (avaliado em bancada e em veículo), mas elencaremos também outros necessários direcionadores para a construção de uma unidade de ar condicionado realmente efetiva para essa aplicação.

\subsection{O evaporador dotado de acumulador}

O princípio do evaporador dotado de acumulador (ou "Storage-Evaporator") é a adoção de um acumulador preenchido por um material ("PCM - Phase-Change Material") que tem a característica física de executar a mudança de fase durante o ciclo de operação do compressor do sistema de ar condicionado. Melhor dizendo, tal veículo se solidificaria numa temperatura superior à temperatura de descarga definida no sistema de ar condicionado e quando o compressor se desligasse (por exemplo, durante os períodos de "Stop"), este veículo seria ainda capaz de fornecer "frio" (retirando energia do ambiente necessária ao processo de mudança de fase do "PCM" - do estado sólido para o estado líquido) para a massa de ar circulante por um período suficiente para a manutenção da sensação de conforto para o usuário no habitáculo.

\subsubsection{Características construtivas do evaporador com acumulador}

As alternativas para a construção do evaporador com acumulador podem ser diversas, como ilustramos na figura 3. Podemos ter um acumulador integrado, construído juntamente com o evaporador padrão (1), podemos tê-lo independentemente construído e integrado por um bloco na válvula de expansão térmica (TXV) (2), podemos tê-los simplesmente acoplados à frente do evaporador padrão (add-on, sem integração - 3).
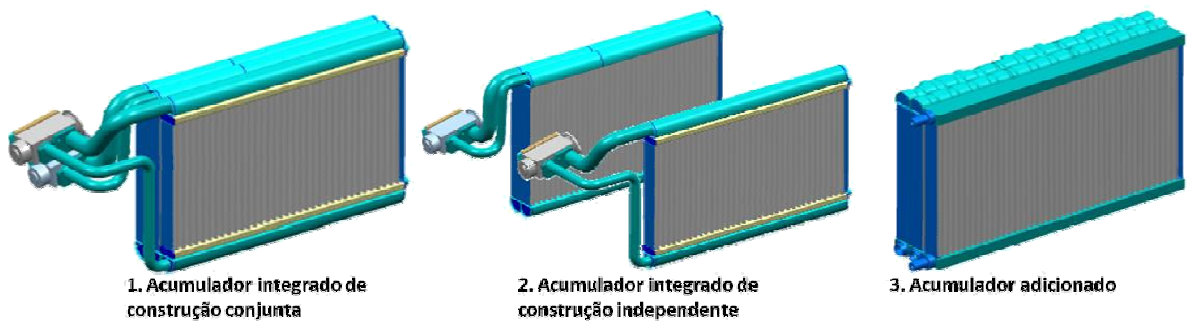

Figura 3: Alternativas construtivas para o evaporador com acumulador

As alternativas (1) e (2) da figura acima possuem características internas semelhantes e forma projetados para que a transferência de energia para o acumulador seja realizado tanto pelo ar - "ar frio vindo do evaporador padrão" - quanto pelo refrigerante - por meio da característica construtiva "tube-in-tube", conforme mostrado na figura 4, abaixo: 


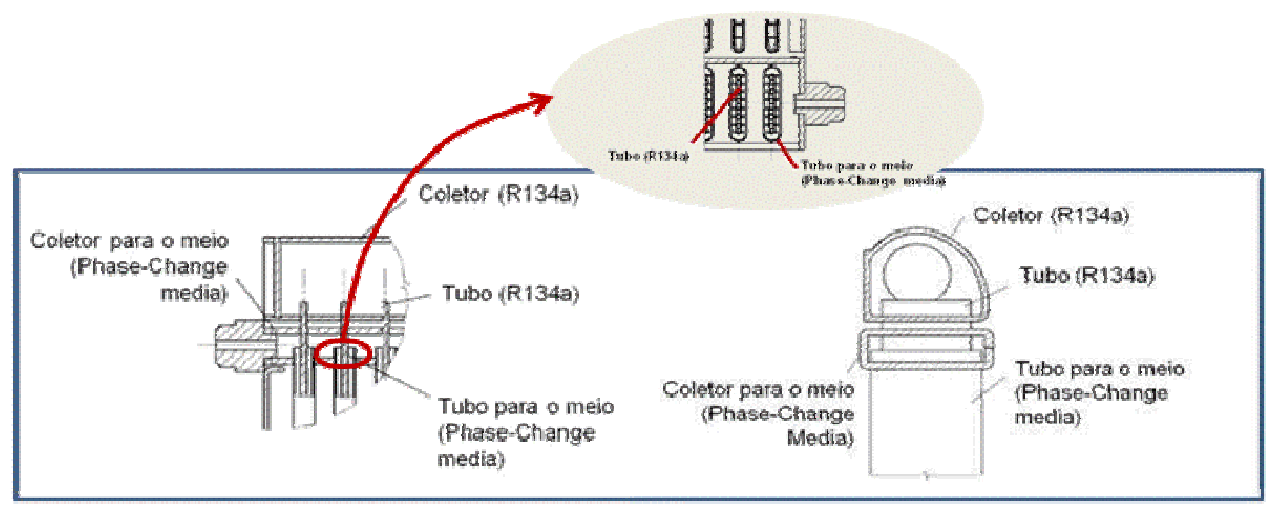

Figura 4: Ilustração do sistema "tube-in-tube" para o evaporador com acumulador

A alternativa (3) utiliza-se somente do carregamento via fluxo de ar, o que equivale a dizer que: $\mathrm{Na}$ condição de $100 \%$ recírculo (sem admissão de ar fresco e onde uma vazão de ar de $4 \mathrm{~kg} / \mathrm{min}$. é alcançada), considerando-se uma temperatura de descarga da ordem de 2 graus Celsius (para que se possa prevenir o congelamento no evaporador) e um diferencial de temperatura mínimo para que ocorra a transferência de calor de 3 Kelvin, teríamos:

$$
\dot{Q}_{\text {air } \text { max }}=\dot{m}_{\text {air }} \cdot c \cdot \Delta T=4 \frac{\mathrm{kg}}{\min } \cdot 1 \frac{\mathrm{kJ}}{\mathrm{kgK}} \cdot 3 \mathrm{~K}=12 \frac{\mathrm{kJ}}{\min }
$$

Onde:

$\mathbf{Q}_{\text {air }, \text { max }}=$ Calor

$\mathbf{m}_{\text {air }}=$ vazão em massa do ar

$\mathbf{c}=$ coeficiente de transmissão

$\boldsymbol{\Delta} \mathbf{t}=$ diferença de temperatura

$\mathrm{O}$ que equivale a dizer que uma demanda de energia acumulada de $60 \mathrm{~kJ}$, demoraria em torno de 5 minutos para ter o "PCM" congelado, o que é totalmente inviável para os ciclos urbanos[6].

As alternativas (1) e (2) por sua vez, além do carregamento via fluxo de ar utilizam-se do carregamento proporcionado pelo fluído refrigerante (neste caso, R134a), habilitando o congelamento do "PCM" do acumulador em tempos menores que 1 minuto, conforme o perfil mostrado na figura 5 de acordo com a simplificação constituída a partir da proposta de descrição matemática para o fenômeno de solidificação/fusão dos fluídos (problema de Stefan - transferência de calor unidirecional e somente por difusão):

$$
t=\frac{h_{E} \rho s^{2}}{2 \lambda\left(\vartheta_{E}-\vartheta_{0}\right)}\left(1+2 \frac{\lambda}{s}\left[\frac{\delta_{W}}{\lambda_{W}}+\frac{1}{\alpha}\right]\right)
$$

Onde: 
$t$ = tempo de solidificação do PCM

$\lambda=$ coeficiente de condutividade térmica

$\delta_{w}=$ espessura da parede do tubo PCM

$h_{E}=$ entalpia (solidificação)

$\rho=$ densidade

$s=$ dimensão do tubo que contém o PCM

$\lambda_{W}=$ coeficiente de condutividade térmica PCM

$\alpha=$ difusividade térmica

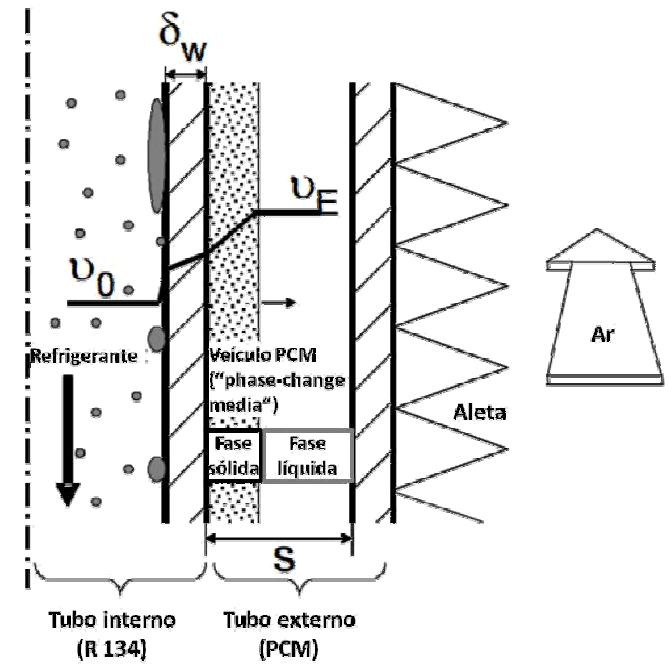

Figura 5: Perfil de temperatura do carregamento pelo fluido refrigerante

\subsubsection{Determinação dos requisitos e avaliação}

De outro lado, a percepção de conforto térmico por parte dos ocupantes da cabine é influenciada diretamente por uma série de parâmetros relacionados às condições de ambiente (temperatura de bulbo-seco, umidade relativa, temperatura do meio radiante, circulação do ar) bem como parâmetros relacionados aos ocupantes (taxas metabólicas, tipos de vestimenta). Ainda: a modificação de um desses parâmetros pode reestabelecer a percepção de conforto com uma mínima transferência de energia, quer seja esta subtraída ou adicionada [7]. Logo, para regiões significativamente distintas com relação ao clima, às condições de rodagem, os resultados podem variar em grande intensidade. Em vista de tantas variáveis, faz-se necessário determinar as condições adequadas para uma efetiva avaliação.

A determinação dos requisitos para o dimensionamento do sistema dotado de evaporador com acumulador foi baseada em investigações realizadas na Alemanha, no estado de Baden-Württenberg, na cidade/região metropolitana de Stuttgart. Primeiramente, definiu-se um ciclo de rodagem (avaliação/uso) abrangendo porções metropolitanas significativas, de acordo com a figura 6. 


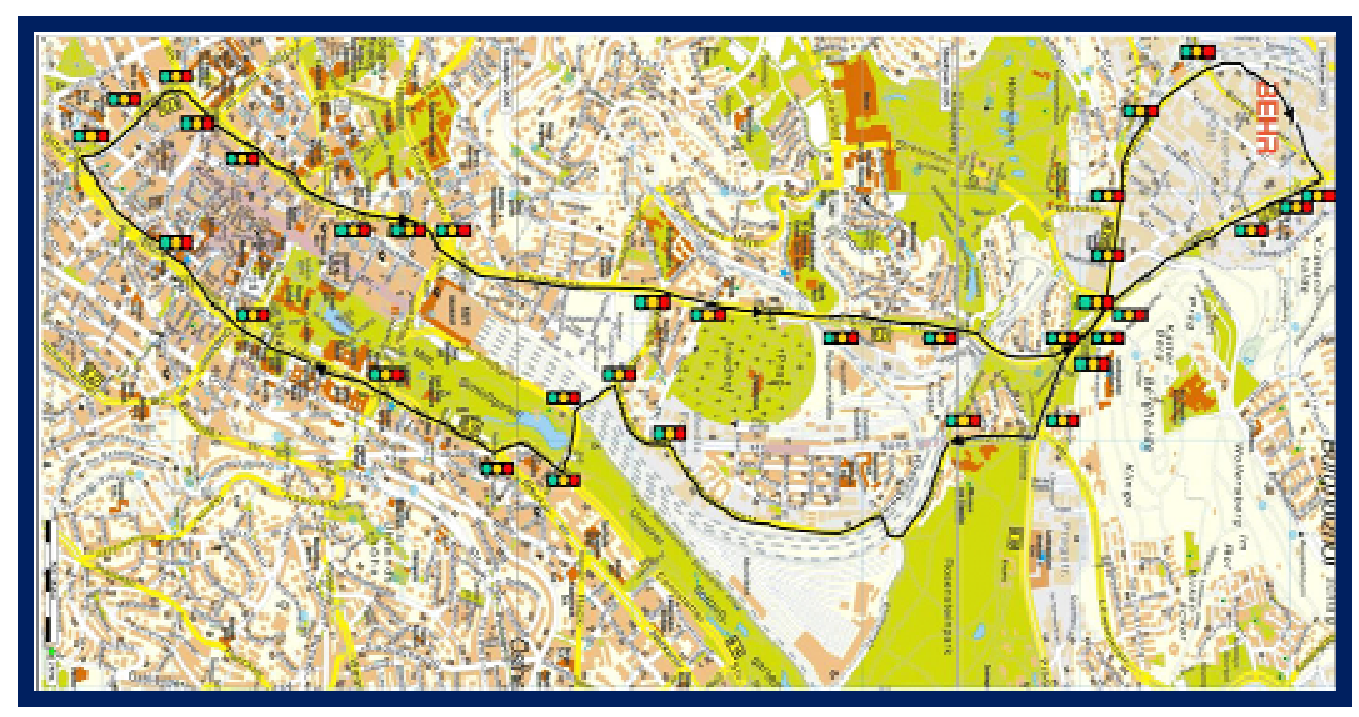

Figura 6: Ciclo urbano determinado para a avaliação

Este ciclo de rodagem, complementado com dados regionais vastos e amplamente disponíveis resultaram na determinação da frequência e duração das paradas realizadas que podemos caracterizar como sendo [6]:

- Tempo entre as paradas: No intervalo de 16 a 28 segundos;

- Tempo parado: $90 \%$ até 40 segundos;

- Intervalo parado: entre 2 a 65 segundos;

- Tempo de rodagem normal (“idle-off”): $22 \%$ do ciclo;

Outras considerações [6]: As medições sempre partiram de veículo já com a cabine refrigerada ("cool-down" já executado). O veículo está com a admissão de ar fresco fechada (está em 100\% recírculo) e a temperatura externa está 15 Kelvin acima da temperatura do habitáculo, necessidade de retirar-se de 2,2 a $3,3 \mathrm{~kW}$ de calor do habitáculo, COP de 1,7 em marcha lenta, o que nos leva a uma demanda de 1,3 a $2 \mathrm{~kW}$ no compressor. Outra condição é que o sistema não manterá a temperatura constante durante as paradas, mas sim buscará preservar a sensação de conforto. Esta sensação de conforto estaria delimitada pela temperatura de $15 \mathrm{vC}$ (na cabine) a uma umidade relativa de $100 \%$. Ainda de acordo com as mesmas fontes, tais considerações e simplificações nos levam para os seguintes requisitos, que cobrem até $95 \%$ do total de paradas caracterizadas acima:

- Conforto: Limiar definido quando a temperatura de descarga no evaporador alcançar $11 \mathrm{vC}$.

- Manutenção do limiar de conforto (condicionados para um dia quente- 30 a $35 \mathrm{vC}$, com radiação solar) por 40 segundos. Expectativa de 50 segundos para dias mais amenos $(25 \mathrm{vC}$ com radiação solar ou $30 \mathrm{vC}$ sem radiação solar).

\subsubsection{Avaliação em veículo e em bancada}

Uma avaliação preliminar em bancada foi realizada comparando as respostas de um evaporador padrão e de um evaporador com acumulador. Os pontos medidos foram feitos utilizando-se ar seco $(<0 \mathrm{vC})$ para evitar a influência do 
condensado na temperatura de descarga. Todas as medições consideraram uma vazão de ar de $4 \mathrm{~kg} / \mathrm{min}$. (característica de 100\% recírculo). As temperaturas de admissão de ar no evaporador foram estabelecidas em $25 \mathrm{vC}$ e $30 \mathrm{vC}$. As figuras 7 e 8 ilustram os resultados obtidos em bancada bem como os requisitos anteriormente definidos.

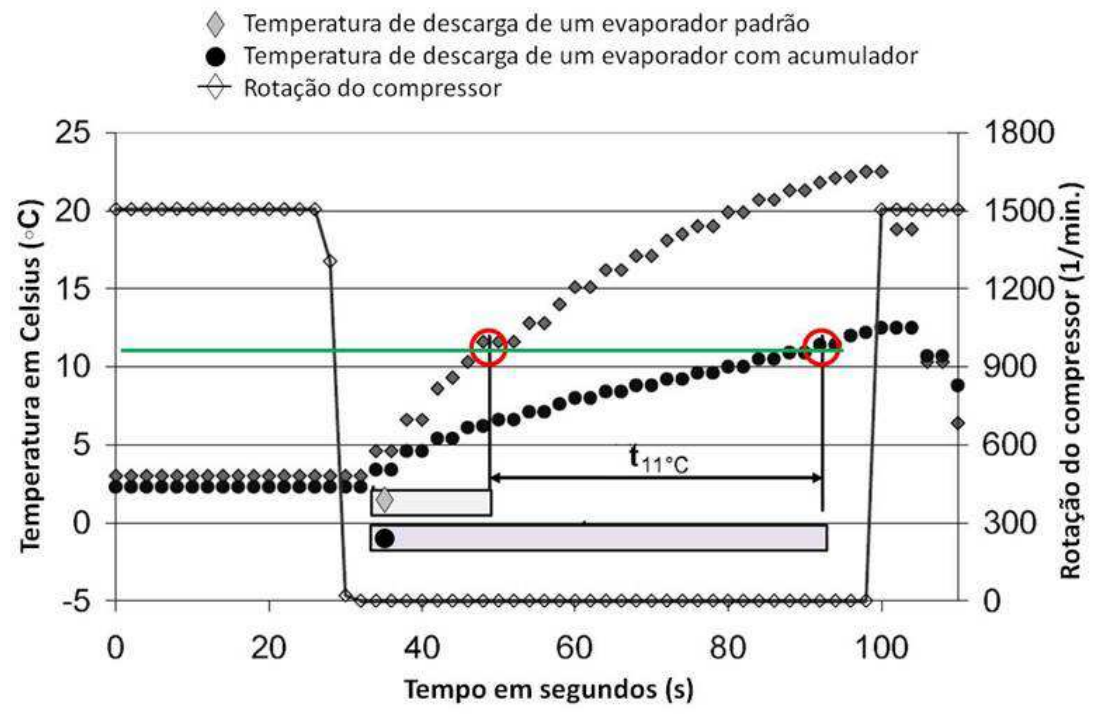

Figura 7: Comportamento da temperatura de descarga após o desligamento do compressor - Evaporador padrão x Evaporador com acumulador

$\mathrm{O}$ evaporador com acumulador foi integrado a uma unidade de ar condicionado de um veículo de alta gama (Mercedes Benz E-Class). Como podemos ver na figura 8, com uma unidade de ar condicionado convencional, o limiar de 11 vC (para temperatura de descarga) é alcançado entre 7 e 10 segundos (de acordo com a temperatura de entrada de ar no evaporador). Quando o evaporador com acumulador foi integrado a unidade de ar condicionado o tempo para o limiar de $11 \mathrm{vC}$ foi alcançado na faixa de 40 a 55 segundos.

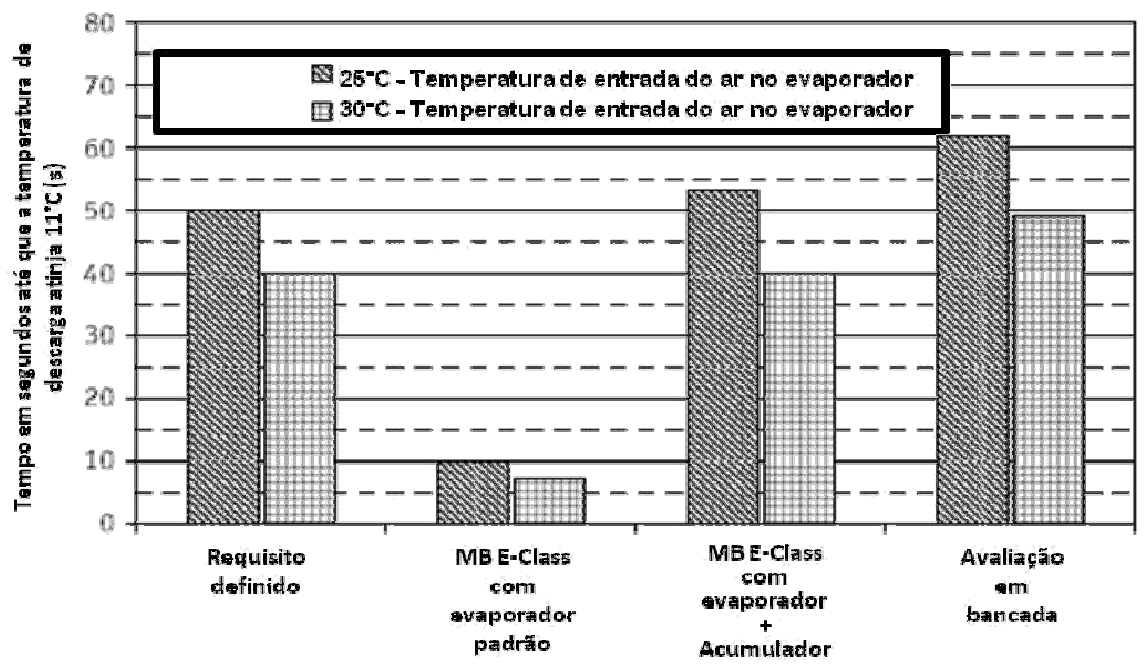

Figura 8: Comparação do tempo para alcançar o limiar de 11 graus Celsius para a temperatura de descarga 
O comportamento dinâmico também é de fundamental importância para caracterizar os resultados obtidos. A figura 9 mostra o tempo necessário para a recuperação do pleno potencial de absorção de energia (por parte do PCM) em função da temperatura de entrada do ar no evaporador. Pode-se afirmar que em 60 segundos de funcionamento do compressor, o PCM recobrou 90\% de sua capacidade.

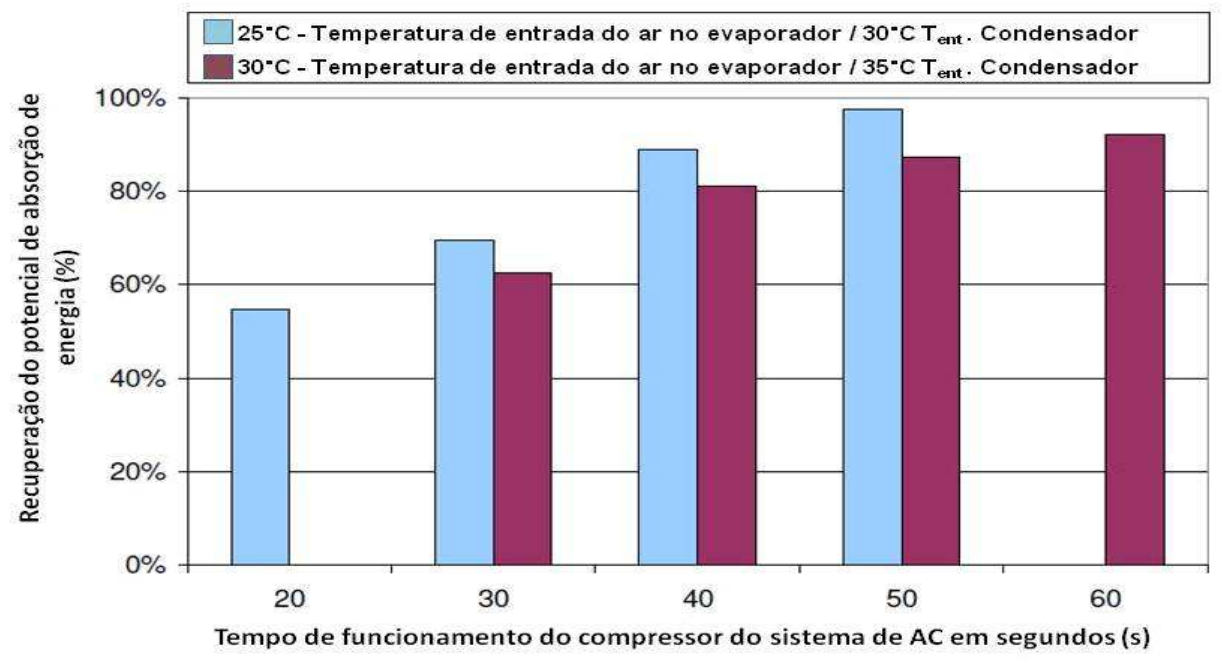

Figura 9: Comportamento dinâmico do veículo PCM

1.2. Demais direcionadores de projeto de uma unidade de ar condicionado que resultam em economia de combustível

O real consumo de combustível atribuído às demandas do sistema de ar-condicionado não é considerado nas medições (os ciclos de avaliação/uso não determinam medições do consumo do veículo com o ar-condicionado ligado), mas sim calculado baseado em aprovações-tipo que levam em consideração uma abordagem reducionista caracterizada por modelos generalizados (mesmo ciclo de avaliação/uso) e condições pré-estabelecidas oriundas de medições controladas do veículo na pista. Os reducionismos nas aprovações-tipo podem acarretar descolamentos entre os valores reais e aqueles medidos na aprovação-tipo de até 20\% [8]. A desconsideração da efetiva contribuição do ar-condicionado para o consumo de combustível pode ser entendida como um fator inibidor à incorporação de tecnologias mais atualizadas e/ou alternativas. Isso equivale a dizer que as possíveis contribuições inerentes às características tecnológicas e/ou construtivas da unidade de ar-condicionado, até o presente momento, não são prioridades na avaliação das montadoras visto que a sua parcela de contribuição para a redução do consumo de combustível não é possível de ser identificada nos ciclos de avaliação/uso hoje em vigor (ou são sensivelmente subestimadas, em ciclos onde são avaliadas), logo não tornam o veículo avaliado elegível aos incentivos que comporiam uma contra partida aos custos de implantação dessas novas tecnologias. Levando-se em consideração que a eficiência no consumo de combustível mantenha-se como o principal direcionador de compras [9], podemos elencar as seguintes contribuições tecnológicas na unidade de ar-condicionado e seus respectivos impactos no consumo de combustível [6]: 


\subsubsection{Estratégias de controle}

A temperatura de descarga do evaporador quando elevada ao limite máximo proporciona menor demanda de refrigeração e por consequência menor demanda de consumo. O risco está no tempo de permanência elevado na máxima temperatura de descarga o que pode gerar odores provenientes do vapor. Tratamentos superficiais hidrofílicos bem como geometrias que diminuam a possibilidade de acumulo de vapor/água resolvem esse efeito colateral.

$\mathrm{O}$ ar fresco admitido carrega consigo porção considerável de umidade na forma de vapor que, em contato com a superfície do evaporador converte-se em água. Esse processo de conversão de fase (latente) "rouba" parcela da capacidade de refrigeração do evaporador (capacidade esta que é formada pela parcela latente e pela parcela sensível). Em termos de balanço, a diminuição da conversão de vapor em líquido (condensado) por parte do evaporador é altamente desejada, aumentando assim o potencial da parcela sensível (ou reduzindo a demanda de refrigeração caso a parcela sensível permaneça constante). Assim sendo, um controle na admissão de ar pode resultar positivamente na demanda de refrigeração e consequentemente no consumo de combustível. No limite, caso a admissão de ar fresco seja completamente fechada, testes em veículo realizado em túnel de vento $(28 \mathrm{vC}, 40 \%$ de umidade relativa e desconsiderando totalmente a radiação solar) mostram uma economia de até $35 \%$ do consumo demandado quando comparado ao teste feito nas mesmas condições, mas admitindo somente ar fresco.

\subsubsection{Redução do calor ganho ("heat pick-up”)}

Esse ganho de energia pode ocorrer na unidade de ar condicionado, ao logo do caminho da admissão do ar, seu resfriamento pelo evaporador e seu encaminhamento para as saídas no painel. Assim sendo, aperfeiçoamentos na unidade devem diminuir o ganho de energia parasita e, portanto, reduzir a demanda por refrigeração e o consumo de combustível. A figura 10 mostra os carregamentos de energia numa unidade de ar condicionado, levando-se em consideração uma temperatura ambiente de $24 \mathrm{vC}$, e $700 \mathrm{~W} / \mathrm{m}^{2}$ de radiação solar. 


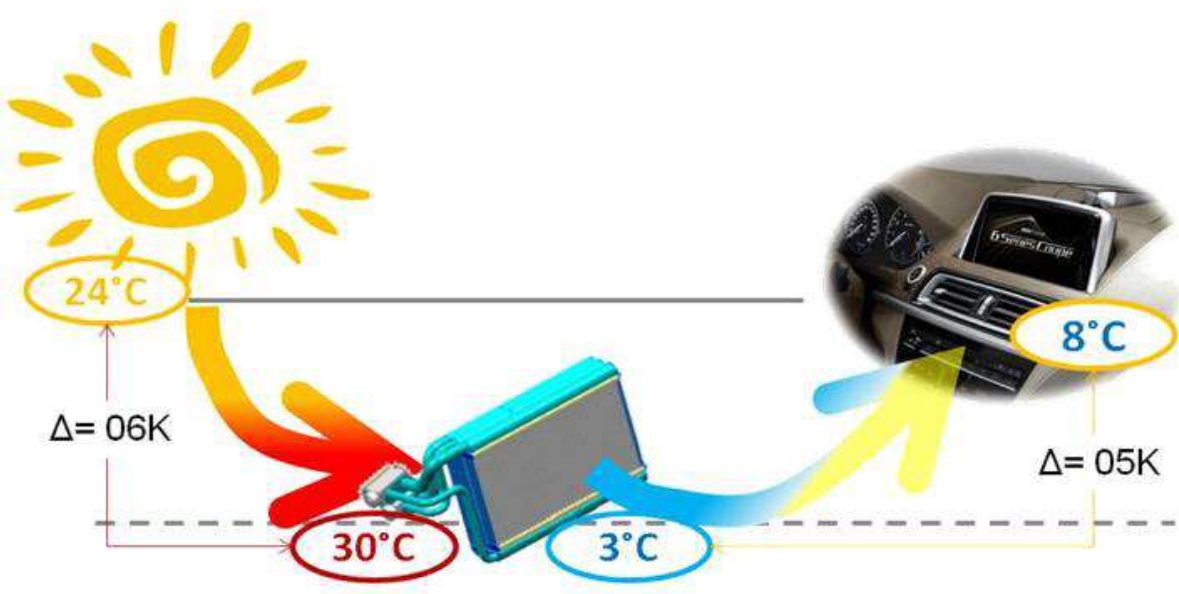

Figura 10: Carregamento de energia na unidade de ar condicionado O ganho de temperatura na entrada pode ser diminuído, por exemplo, com a adoção de controle de velocidade do ventilador via PWM ("Pulse-Width Modulation") que "adiciona" menos calor ao sistema (em comparação com os resistores e controladores lineares). Outra medida necessária, já à frente do evaporador, é a vedação mais eficiente do aquecedor da unidade bem como soluções de dutos mais refratárias ao ganho de energia (ou, caminhos muito mais curtos entre o evaporador e as saídas de ar). Quando o ganho de energia for reduzido em 4 Kelvin, a demanda de refrigeração será reduzida em até 10\% (cálculos realizados com um veículo de média gama).

\subsubsection{Redução do consumo elétrico}

Numa unidade de ar condicionado, as cargas elétricas dos ventiladores e seus controladores chegam a $50 \%$ do total demandado. Lembrando que, usualmente, o fornecimento de energia elétrica por gerador com fator de eficiência de 0,6. Testes realizados em veículo e levando-se em consideração o perfil climático da cidade de Frankfurt na Alemanha, mostram uma redução potencial na demanda elétrica de até $40 \mathrm{~W}$ quando usamos um ventilador controlado por PWM (em comparação com um ventilador com controlador linear), conforme mostra a figura 11. 

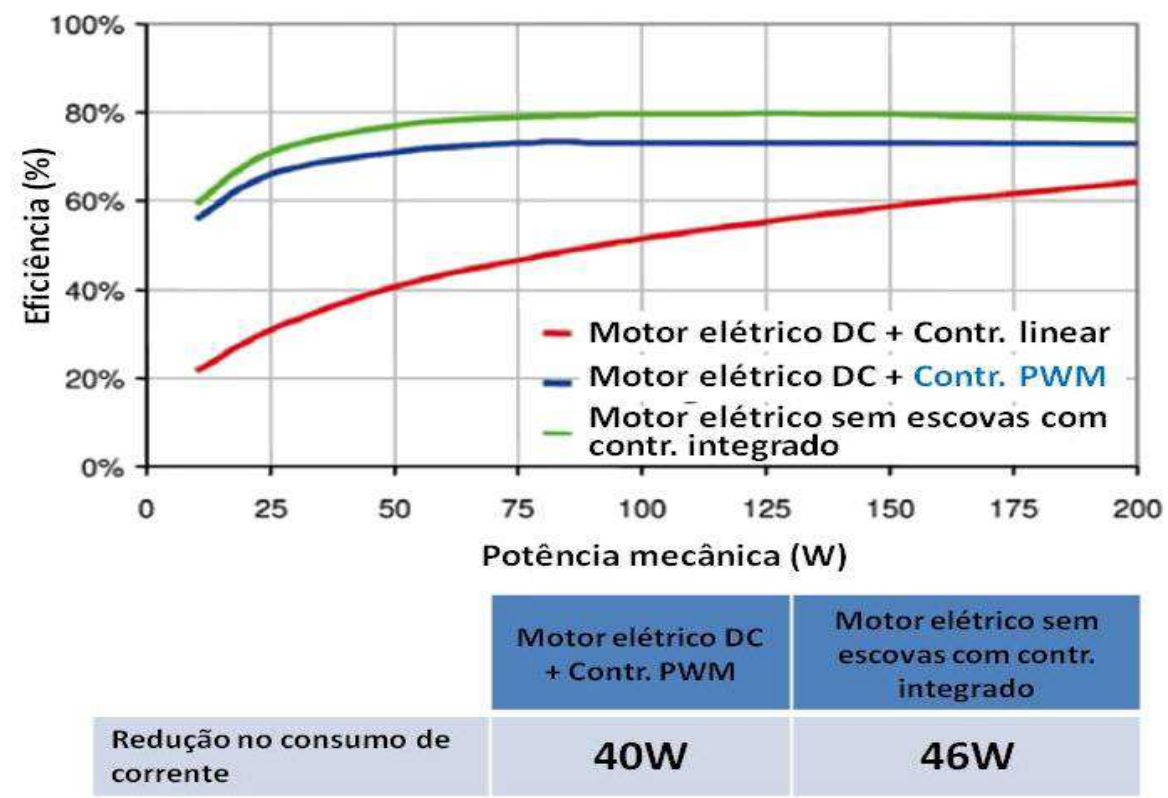

Figura 11: Comparação de eficiência e consumo corrente para soluções de ventiladores

A utilização de motores elétricos sem escovas e com controladores integrados pode proporcionar uma redução no consumo de corrente de adicionais $6 \mathrm{~W}$.

\subsubsection{Redução na demanda para o compressor}

A demanda para o compressor depende da necessidade de refrigeração que, por sua vez, depende de fatores tais como: temperatura externa, temperatura da cabine, umidade do ar, e da incidência da radiação solar. Uma grande parcela do consumo de combustível atribuído ao sistema de ar condicionado está relacionada com o acionamento do compressor que pode ser racionalizado somente pelo aperfeiçoamento do circuito refrigerante. Elementos tais como os trocadores de calor, quantidade de óleo lubrificante presente no sistema, controle da temperatura na saída do evaporador e regulação do sistema (TXV) devem ser melhorados para que reduções da ordem de $10 \%$ da demanda sejam atingidas.

Uma avaliação realizada em bancada de sistemas numa unidade de série equipada com uma TXV eletrônica identificou os benefícios individuais que estão mostrados na figura 12. Vale ressaltar que ao colocarmos todas as melhorias conjuntamente o resultado foi uma melhora no COP da ordem de $36 \%$ quando em baixa capacidade. Também mostramos a variação da contribuição dos elementos aperfeiçoados quando passamos da baixa capacidade de refrigeração para a alta capacidade de refrigeração.

A instalação de um trocador de calor interno ("Internal Heat Exchange", ou IHX) resulta numa melhora do COP entre 5 e $10 \%$. Este IHX proporciona uma diminuição da temperatura do refrigerante saído do condensador, possibilitando que esse mesmo refrigerante, ao expandir-se no evaporador, possa tomar mais energia. 


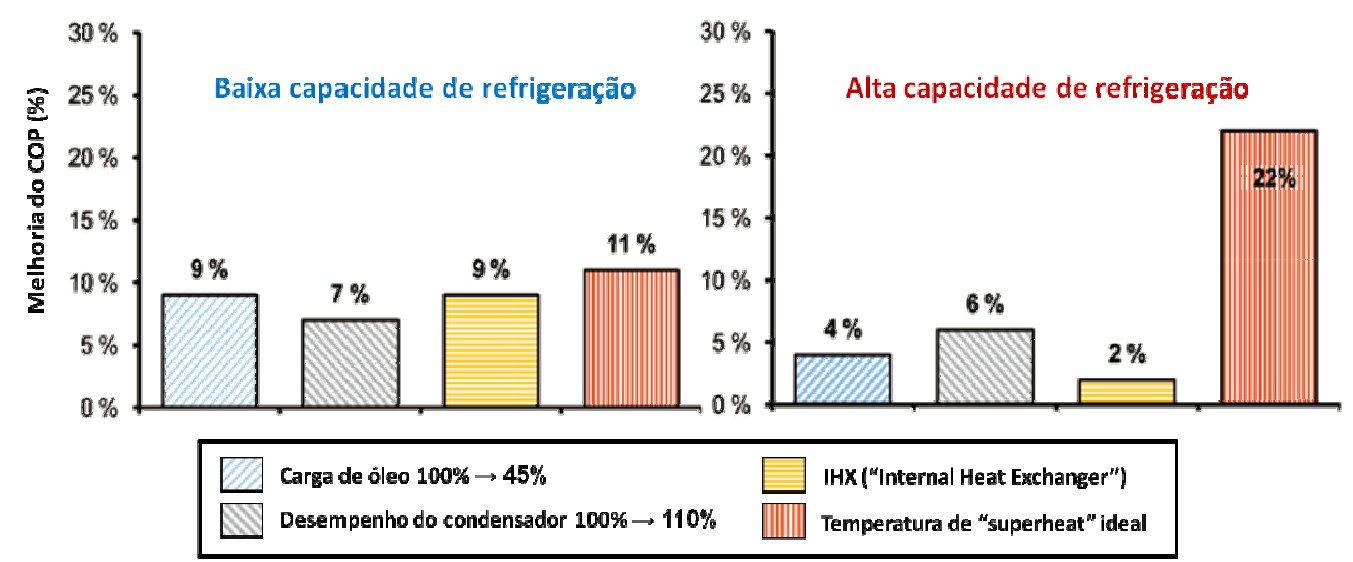

Figura 12: Melhoria do COP com os elementos aperfeiçoados

\subsubsection{Avaliação em veículo}

Um veículo de média gama foi selecionado para receber os elementos aperfeiçoados e ser testado em túnel de vento para uma primeira quantificação dos resultados. A base de comparação foi estabelecida a uma temperatura ambiente de $28 \mathrm{vC}$, umidade relativa em $40 \%$ e com a temperatura da cabine selecionada para $22 \mathrm{vC}$. A unidade de ar condicionado regulada para $100 \%$ de admissão de ar fresco e a temperatura no evaporador, regulada para $3 \mathrm{vC}$ (regulagem padrão) - Dessa forma, o consumo de combustível fica estabelecido na base $100 \%$.

Ao implantarmos a primeira medida, regulando a admissão de ar fresco para $15 \%$ (ou seja $85 \%$ de ar em recírculo), o consumo de combustível foi reduzido para $65 \%$ do valor inicial.

Instalando-se as melhorias nos elementos do circuito refrigerante (item 1.2.4) os benefícios resultaram em redução adicional no consumo de combustível, estabelecendo-se em $35 \%$ do valor inicial.

Ao fixarmos a temperatura de descarga do evaporador em 8vC (no lugar dos $3 \mathrm{vC}$ da regulagem padrão) os patamares de consumo foram para apenas $20 \%$ do valor original.

\section{CONCLUSÃO}

A utilização do evaporador com acumulador em veículos equipados com dispositivo StartStop proporciona, quando há o desligamento do motor, uma janela de tempo de até 40 segundos onde a percepção de conforto permanece - considerando uma temperatura de entrada do ar no evaporador em $30 \mathrm{vC}$ ( e de até 50 segundos quando a temperatura de entrada do ar no evaporador em $25 \mathrm{vC}$ ) o que é suficiente para cobrir em mais de $90 \%$ as paradas no 
circuito urbano definido neste estudo. Logo, para os veículos micro-híbridos é, certamente, um fator habilitador determinante para a consecução dos máximos índices de economia de combustível a que este tipo de veículo se propõe.

A implantação do evaporador com acumulador demanda modificações de ordem simples caso a unidade de ar condicionado seja automaticamente controlada: além do próprio evaporador, pequena mudanças na caixa de ar condicionado permanecendo o restante do sistema inalterado.

Os aperfeiçoamentos adicionais possíveis para o sistema de ar condicionado mostram-se como grandes contribuidores potenciais para a redução do consumo. Vale lembrar mais uma vez, o trabalho de JOHNSON [5] que atribui ao acionamento do sistema de ar condicionado, para a frota dos Estados Unidos um consumo anual da ordem de 27 bilhões de litros de gasolina e que uma redução da ordem de $50 \%$ é possível tendo em vistas os resultados apresentados.

\section{Limitações deste estudo e oportunidades de desdobramento}

Os resultados que apresentaremos para o evaporador com acumulador ("Storage") foram obtidos a partir da determinação de um ciclo de avaliação/uso que considera as condições regionais e de contorno da cidade de Stuttgart, estado de Baden-Wuttenberg na Alemanha e que, obviamente, pressupõe a medição com o ar-condicionado ligado. Dados do nosso país, das nossas condições climáticas e das nossas condições de tráfego urbano devem ser levantados para que possamos ter um ciclo de avaliação que seja representativo. Da mesma forma, um veículo que represente o estado tecnológico da nossa frota deve ser usado.

Também para os aperfeiçoamentos nos elementos do sistema de ar condicionado, entendemos que os métodos de avaliação hoje vigentes guardam pouca aderência com as condições reais de utilização, subestimando as reais demandas do sistema e o consumo de combustível a elas atribuído. Assim, o modelo de avaliação coloca-se como fator inibidor para a proliferação mais acelerada das alternativas tecnológicas já disponíveis e que, certamente, reduziriam a o consumo de combustível, sob a ótica do usuário final. Da mesma forma, nos falta um levantamento nacional para que possamos, com base em dados atualizados, reformular a metodologia de cálculo e assegurar a medição efetiva da influência do ar condicionado no consumo de combustível dos veículos automotores.

\section{REFERÊNCIAS}

[1] BOOK, M., GROLL, M., MOSQUET, X., RIZOULIS, D., STICHER, G. The comeback of the electric car?: How real, how soon and what must happen next. , January 2009, disponível em: https://www.bcgperspectives.com/content/articles/automotive_energy_environment_comebac $\mathrm{k}$ of the electric car/ acesso em 05.12.2012

[2] MOSQUET, X., DEVINENI, M., MEZGER, T., ZABLIT, H., STICHER, G., GERRITS, M., RUSSO, M. - Powering Autos to 2020. , July 2011, disponível em: https://www.bcgperspectives.com/content/articles/automotive_energy_environment_powering _autos_2020_era_electric_car/ acesso em 05.12.2012 
[3] CASSEL, Johnathan (Editor) "Micro-hybrids to be dominant hybrid vehicle type for next 10 years" datado de 04.12.2012 press release IHS media relations, disponível em: http://www.imsresearch.com/press-

release/Microhybrids to be dominant_hybrid_vehicle type for_next_10_years\&from=all_p

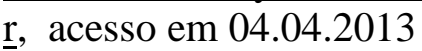

[4] CHEN, K., KAUSHIK, S., HAN, T., GHOSH, D., WANG, M. - Thermal Comfort Prediction and Validation in a Realistic Vehicle Thermal Environment, Abril 2012 - SAE International working paper, $\mathrm{p} 01$

[5] JOHNSON, V. - Fuel Used for Vehicle Air Conditioning: A State-by-State Thermal Comfort-Based Approach, Janeiro 2002 - SAE working paper 2002-01-1957 p.12

[6] MANSKI,R., STRAUSS, T., KOHL, M., WEINBRENNER, M. - Storage EvaporatorsInnovative AC Concept for Micro Hybrid Vehicles, 2006, SAE working paper 06HX-5 p.02,03

[7] ALAHMER, A. , OMAR, M. Vehicular Cabins' Thermal Comfort Zones; Fanger and Berkeley Modeling - Vehicle Engineering (VE) Volume 1, Issue 1, Março 2013, disponível em: http://www.seipub.org/ve/PaperInfo.aspx?ID=2452 ,p.27 acesso em 07.05.2013

[8] MOCK, P., GERMAN, J., BANDIVADEKAR,A., RIEMERSMA, I. Discrepancies between type-approval and "real-world" fuel consumption and $\mathrm{CO} 2$ values - assessment for 2001-2011 European passenger cars. International Council on Clean Transportation working paper 2012-02, Abril, 2012 p.01

[9] KPMG's Global Automotive Executive Survey 2012 - Managing growth while navigating uncharted routes, Janeiro 2012disponível em: http://www.kpmg.com/GE/en/IssuesAndInsights/ArticlesPublications/Documents/Globalautomotive-executive-survey-2012.pdf p.07, acesso em 04.04.2013 